Cilia newborn epithelium oxygen toxicity mucin trachea

\title{
Toxic Effects of Oxygen on Gultured Human Neonatal Respiratory Epithelium
}

\author{
Thomas F. Boat ${ }^{[22]}$, Jerome I. Kleinerman, Avroy A. Fanaroff, and LeRoy W. Matthews \\ Department of Pediatrics, Case Western Reserve University School of Medicine, and the Department of Pathology Research, \\ St. Lukes Hospital, Cleveland, Ohio, USA
}

\begin{abstract}
Extract
Explants of tracheal epithelium from each of six human neonates were exposed to both $80 \%$ and $20 \%$ oxygen under otherwise identical culture conditions. Cessation of ciliary movement and carbon particle transport occurred after 48-96 hr of exposure to $80 \%$ oxygen, but not after $168 \mathrm{hr}$ of exposure to $20 \%$ oxygen.

This alteration of ciliary function was related temporally to squamous metaplasia, or to degeneration and sloughing of cells from the surface epithelium. Explants secreted more mucin and lysozyme during the first 24-72 hr of culture in $80 \%$ oxygen. Thereafter, diminished secretion was observed, apparently related to loss of goblet cells from the surface epithelium and failure to discharge the secretory products of submucosal glands. These findings indicate that high oxygen concentrations at atmospheric pressure alone can cause marked alterations of structure and function in neonatal large airways epithelium. Onset of these changes corresponds to the time when the earliest clinical and cytologic evidence of bronchopulmonary dysplasia has been detected, suggests that similar oxygen-induced changes are produced in vivo. Loss of mucociliary function may be an important pathogenetic component of bronchopulmonary dysplasia.
\end{abstract}

\section{Speculation}

Organ culture of human large airways epithelium appears to be a useful model for study of pulmonary oxygen toxicity. Studies of oxygen concentrations and duration of exposure tolerated by human respiratory epithelium, the cellular mechanisms of oxygen-induced alteration, and the use of pharmacologic agents to prevent or delay onset of toxic changes may be facilitated by using this in vitro technique.

\section{Introduction}

Neonatal lungs which have been exposed to high concentrations of oxygen ( $\mathrm{HiO})$ show marked alteration of epithelial and vascular tissues, especially at the level of terminal airways [13]. No direct evidence demonstrating oxygen-induced changes in large airways of neonates has been presented. Cytologic studies by Northway and Rosan [14] do suggest an early dis- ruption of ciliated epithelium somewhere in the airways of neonates who were exposed to HiO. However, these infants were intubated and ventilated with positive pressure, often for prolonged periods. It is difficult to differentiate the effects of $\mathrm{HiO}$ from these and other potential insults to lung tissue. We have recently developed an organ-culture system for the maintenance of human respiratory epithelium [1] which allows direct observation of the effects of $\mathrm{HiO}$ in controlled 
situations. Changes in mucociliary transport, surface epithelial morphology, and mucin secretion of explants exposed to $80 \%$ oxygen in this culture system are reported.

\section{Materials and Methods}

The tissue source for large airways epithelium was trachea which was removed from six neonates between 1 and $3 \mathrm{hr}$ after death. Gestational ages at birth for the six trachea donors ranged from 24-40 weeks, postnatal survival from less than $24 \mathrm{hr}$ to 28 days. Causes of death included extreme prematurity [2], hypoplastic left ventricle [2], asphyxiating thoracic dystrophy, and trisomy 13-15. None of the subjects had been intubated or exposed to oxygen concentrations higher than $40 \%$.

Tracheas were transported to the laboratory at room temperature in Hank's balanced salt solution containing $100 \mu \mathrm{g} / \mathrm{ml}$ gentamicin and $1 \mu \mathrm{g} / \mathrm{ml}$ amphotericin [17]. Extraneous tissue was removed and each trachea was cut into four full length, full thickness strips. Two strips were placed in each of two preweighed plastic petri dishes ( 50 by $12 \mathrm{~mm}$ ) containing $2.0 \mathrm{ml}$ single strength Medium 199 (Earle's base) to which had been adcled $100 \mu \mathrm{g} / \mathrm{ml}$ gentamicin and $10 \mu \mathrm{g} / \mathrm{ml}$ nystatin [18]. In two experiments, both $1 \times 10^{6} \mathrm{dpm} / \mathrm{ml}^{3} \mathrm{H}-6$ glucosamine and $8 \times 10^{6} \mathrm{dpm} / \mathrm{ml}{ }^{35} \mathrm{SO}_{4}$ were added to the media. Tissue weights were calculated from the difference of petri dish weights before and after addition of tissue. The two petri dishes were then placed in separate incubators. Both contained $5 \% \mathrm{CO}_{2}$ and a water-saturated environment at $35^{\circ}$. One incubator contained $20 \%$ oxygen, the other $80 \%$ oxygen. The high oxygen concentration was continuously monitored and adjusted within a $\pm 1 \%$ range by an IMI oxygen controller [19].

Petri dishes were removed from the incubators at 24-hr intervals. At these times, the surface was illuminated obliquely with a high intensity light source and ciliary movement observed through a dissecting microscope [6]. Sterile India ink diluted with nine parts sterile saline was placed on explant surfaces to confirm the presence or absence of effective ciliary movement. Medium was then removed from each dish after gentle irrigation of explants to remove the existing mucus layer, and immediately replaced with fresh medium. Harvested media were stored at $-20^{\circ}$ until completion of the experiment.

Before culture, and after 96 and $168 \mathrm{hr}$ of incubation, pieces of tissue selected randomly were cut from tracheal strips and fixed in Bouin's solution or buffered neutral formalin. These tissues were subsequently processed for histologic and histochemical examination. In addition to routine staining with hematoxylin and eosin, tissue sections were stained sequentially with Alcian blue $(\mathrm{AB})$ at $\mathrm{pH} 2.5$ and periodic acidSchiff (PAS) [12].

Samples of media designated for analysis were thawed, dialyzed individually against four changes, 300 volumes each, of distilled water over a $72--96-\mathrm{hr}$ period, lyophilized, and taken up in a fixed volume of distilled water. Determinations performed on these samples include: (1) lysozyme by the radial diffusion method of Osserman and Lawlor [15], (2) sialic acid by the thiobarbituric acid assay of Warren [16], (3) fucose by the $\mathrm{H}_{2} \mathrm{SO}_{4}$-cysteine method of Dische and Danilchenko [5], and (4) blood group activity by a microtitrametric method [7]. Tritium and ${ }^{35} \mathrm{SO}_{4}$ were counted simultaneously in Bray's solution at $59 \%$ efficiency for ${ }^{35} \mathrm{~S}$ with a $2.4 \%$ contribution of ${ }^{3} \mathrm{H}$, and at $39 \%$ efficiency for ${ }^{3} \mathrm{H}$ with a $24.4 \%$ contribution of ${ }^{35} \mathrm{~S}$.

Chromatographic and electrophoretic studies were performed on explant secretions which had been reduced with $5 \mathrm{~mm}$ dithiothreitol in the presence of $8 \mathrm{M}$ urea, alkylated, and then dialyzed extensively with dilute buffer [2]. Chromatographic fractionation of these secretions was carried out on a column $(2.5$ by $90 \mathrm{~cm}$ ) of Bio-Gel A-5 equilibrated with a solution containing $50 \mathrm{~mm} \mathrm{NaCl}$ and $10 \mathrm{~mm}$ Tris- $\mathrm{HCl}(\mathrm{pH} 7.0)$. Samples (5 $\mathrm{ml}$ ) which contained approximately $10 \mathrm{mg}$ protein were eluted by upward flow with the same solution. Discontinuous polyacrylamide gel electrophoresis of reduced and alkylated secretions was carried out by the method of Davis [4]. After electrophoresis, gels were cut into $1.0-\mathrm{mm}$ slices, each slice was solubilized in 0.2 $\mathrm{ml} 30 \%$ hydrogen peroxide, and this solution counted as clescribed above.

\section{Results}

In the presence of $20 \%$ oxygen ciliary motility of explant surfaces was not perceptibly altered after 7 days of culture. Transport of carbon particles proceeded at a rate between 1.0 and $1.5 \mathrm{~cm} / \mathrm{min}$ on strips of trachea cultured in $20 \%$ oxygen at all intervals up to 7 days after initiation of culture. In contrast, slowing of ciliary movement and focal inactivity of cilia were noted consistently after $48 \mathrm{hr}$ of exposure to $80 \%$ oxygen. All ciliary activity had ceased after 72 or $96 \mathrm{hr}$ in $80 \%$ oxygen (Table I). No movement of carbon particles was noted after $48-96 \mathrm{hr}$ of culture in $80 \%$ oxygen. 
Table 1 . Effect of $80 \%$ oxygen on ciliary function of cultured human tracheal epithelium

\begin{tabular}{cccc}
$\begin{array}{c}\text { Oxygen } \\
\text { concentra- } \\
\text { tion, } \%\end{array}$ & $\begin{array}{c}\text { Number } \\
\text { of experi- } \\
\text { ments }\end{array}$ & $\begin{array}{c}\text { Cessation of all } \\
\text { ciliary movement, hr }\end{array}$ & $\begin{array}{c}\text { Cessation of particle } \\
\text { transport, hr }\end{array}$ \\
\hline 20 & 6 & Did not cease & Did not cease \\
80 & 6 & $72-96$ & $48-96$ \\
\hline
\end{tabular}

Excellent preservation of ciliated and goblet cells in the surface epithelium was observed after both 96 and $168 \mathrm{hr}$ of culture in $20 \%$ oxygen (Figs. 1, 2, and 3). Focal necrosis of deep submucosal glands was noted in these explants and is considered to be the result of hypoxia created by an excessive oxygen gradient between the surface and deeper portions of the explants.

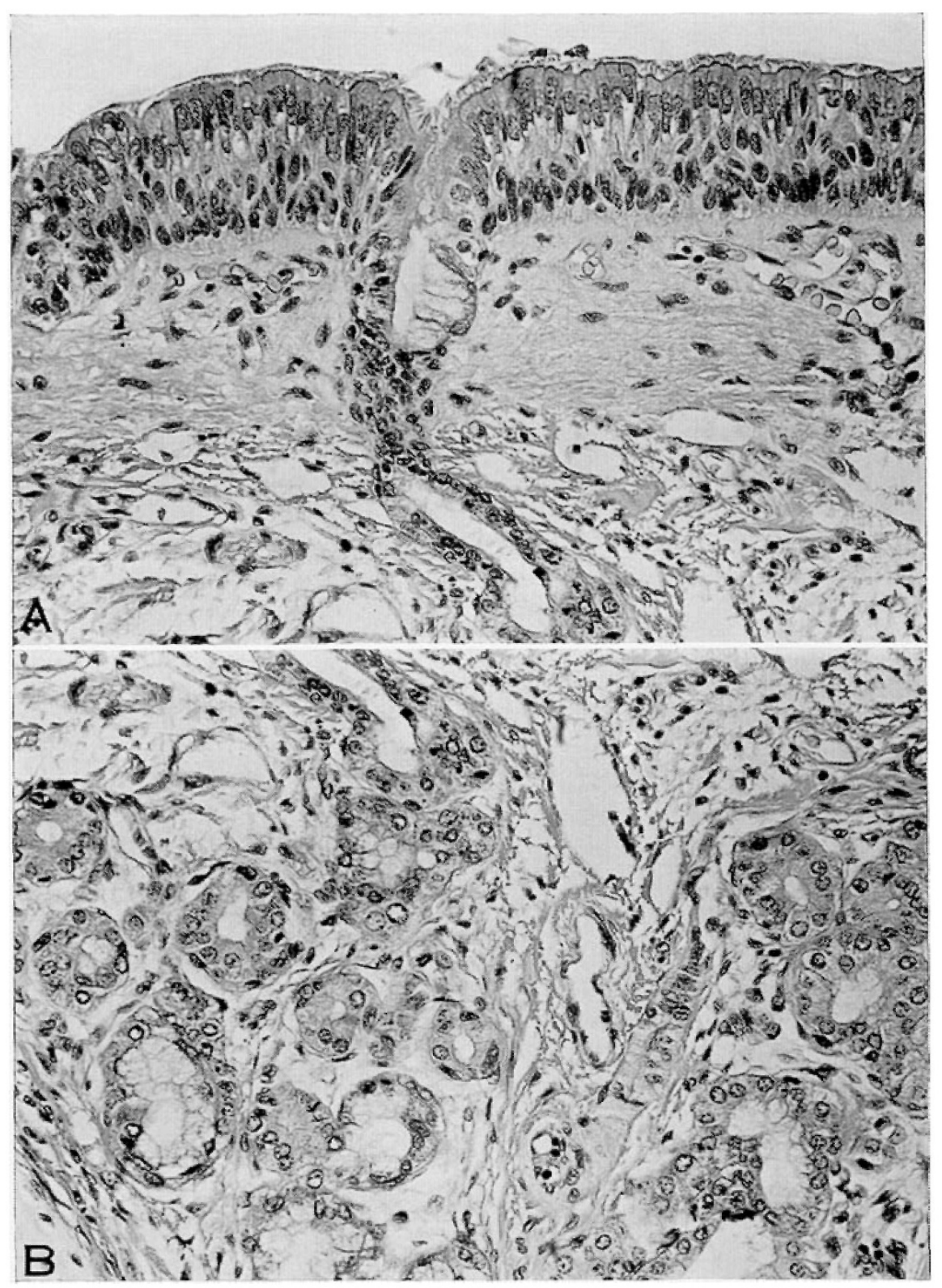

Fig. 1. A: Preculture. This photomicrograph and all others (Figs. 2-5) show preculture or explant tracheal tissue from a single experiment. The tissue donor was an infant with asphyxiating thoracic dystrophy who died before $24 \mathrm{hr}$ of age. The pseudostratified ciliated columnar epithelium is histologically normal. Cilia can be seen. $\times 250$; hematoxylin and eosin. B: Preculture. Submucosal glands are well preserved. Both serous acini and mucus acini with so-called serous demilunes are seen. Little retained luminal secretion is present. $X 250$; hematoxylin and eosin. 


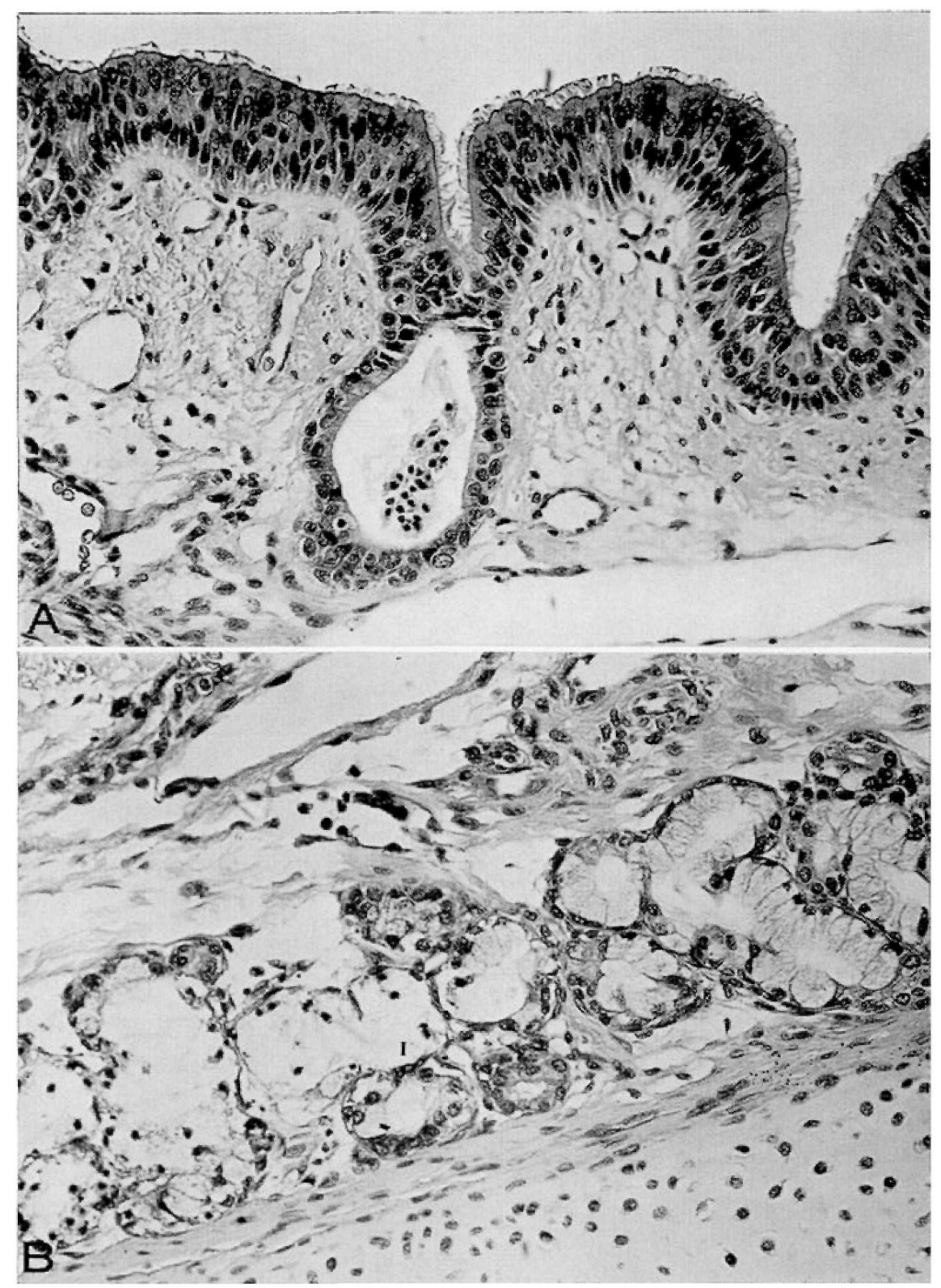

Fig. 2. A: 96 -hr culture, $20 \%$ oxygen. The pseudostratified ciliated columnar epithelium, including the basal cell layer, is well preserved. Degenerating epithelial cells are seen within a duct lumen. $\times \quad 250$; hematoxylin and eosin. B: 96-hr culture, 20\% oxygen. The gland structures at the right of the photograph are well preserved. Those to the left show degeneration, exfoliation, and pyknosis. This demonstrates the improved preservation of superficial and peripheral glands of explants cultured in $20 \%$ oxygen. $\times 250$; hematoxylin and eosin.

More superficial submucosal glands were well preserved after both intervals in culture. Material staining with AB-PAS was present in both the goblet cells of surface epithelium and in cells and lumina of intact submucosal glands after 4 and 7 days of exposure to $20 \%$ oxygen.

Marked histologic changes were noted in explants cultured in $80 \%$ oxygen for these intervals (Figs. 4 and
5). At $96 \mathrm{hr}$, and even more impressively at $168 \mathrm{hr}$, the pseudostratified architecture of surface epithelium was disrupted. Ciliated surface cells became round and appeared to be in the process of desquamation. Many surface cells were no longer ciliated. In some areas metaplasia of surface epithelium to a stratified squamous type occurred. In other areas only a single layer of basal cells remained. No goblet cells were seen. Sub- 


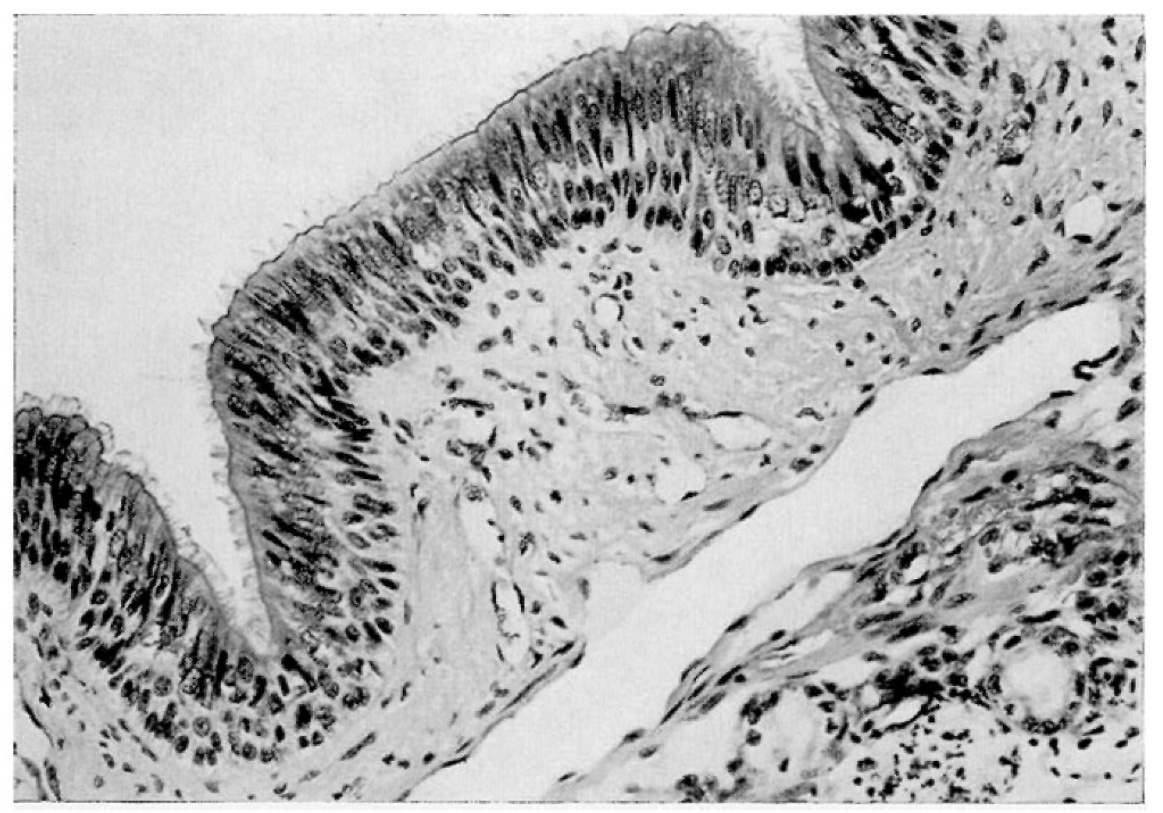

Fig. 3. One hundred sixty-eight-hour culture, $20 \%$ oxygen. The surface epithelium remains intact in its original pseudostratified, ciliated form. At the lower right margin several poorly preserved submuco:al gland acini can be seen. $X 250$; hematoxylin and cosin.

mucosal gland cells, on the other hand, were uniformly intact. Many of these glands were dilated and had accumulated large amounts of intracellular and intraluminal AB-PAS-positive material.

Two of these experiments also were designed to assess the secretion of mucins and other macromolecules by explants in both $20 \%$ and $80 \%$ oxygen. In these experiments both ${ }^{3} \mathrm{H}-6$-glucosamine and ${ }^{35} \mathrm{SO}_{4}$ were added to the culture medium. At least $80 \%$ of the nondialyzable label in spent culture medium behaved chromatographically and electrophoretically like high molecular weight mucin. This major portion of labeled macromolecules, after reduction and alkylation, was eluted from a column of Bio-Gel A- 5 with the void volume. The void volume material stained intensely with PAS and failed to penetrate $7.5 \%$ polyacrylamide gels after electrophoresis at $\mathrm{pH} 8.4$ for $3 \mathrm{hr}$. The remaining $20 \%$ of the nondialyzable label was incorporated into smaller macromolecules which penetrated $7.5 \%$ polyacrylamide gels and were probably nonmucin glycoproteins. On the basis of these data, quantitation of radioactivity in dialyzed media was used to estimate the production and discharge of mucins by explants.

Discharge of labeled mucin (tritiated and ${ }^{35} \mathrm{SO}_{4}$-labeled macromolecules) in the presence of $80 \%$ oxygen equaled or exceeded mucin discharge in the presence of $20 \%$ oxygen for the first $48-72 \mathrm{hr}$ in culture (Fig. 6).
Thereafter, discharge of labeled mucin was consistently greater in the presence of $20 \%$ oxygen. Similarly, titers of secreted blood group active mucin in the media were identical after 24-48 hr in culture, but declined more rapidly thereafter in the presence of $80 \%$ oxygen. Secretion of macromolecular fucose and sialic acid, and of the nonmucin protein lysozyme, was also diminished after 2-3 days in $80 \%$ oxygen (Fig. 7 ).

\section{Discussion}

An adverse effect of $\mathrm{HiO}$ at atmospheric pressure on human tracheobronchial epithelium has never been documented under controlled experimental conditions. Postmortem studies of lungs exposed to $\mathrm{HiO}$ demonstrate marked changes of bronchiolar epithelium [13], but observations of changes in larger airways epithelium have not been communicated. An additional problem with interpretation of previous studies is that the tissues have usually been simultaneously exposed to prolonged positive pressure ventilation and other potential sources of injury such as endotracheal intubation and suction, altered humidity, infection, and drugs. Observed changes, therefore, have not been unequivocally oxygen-induced [3]. In one study with a design more appropriate for the determination of oxygen-induced changes, cat tracheal mucus flow was markedly impaired after a brief exposure to $100 \%$ oxy- 


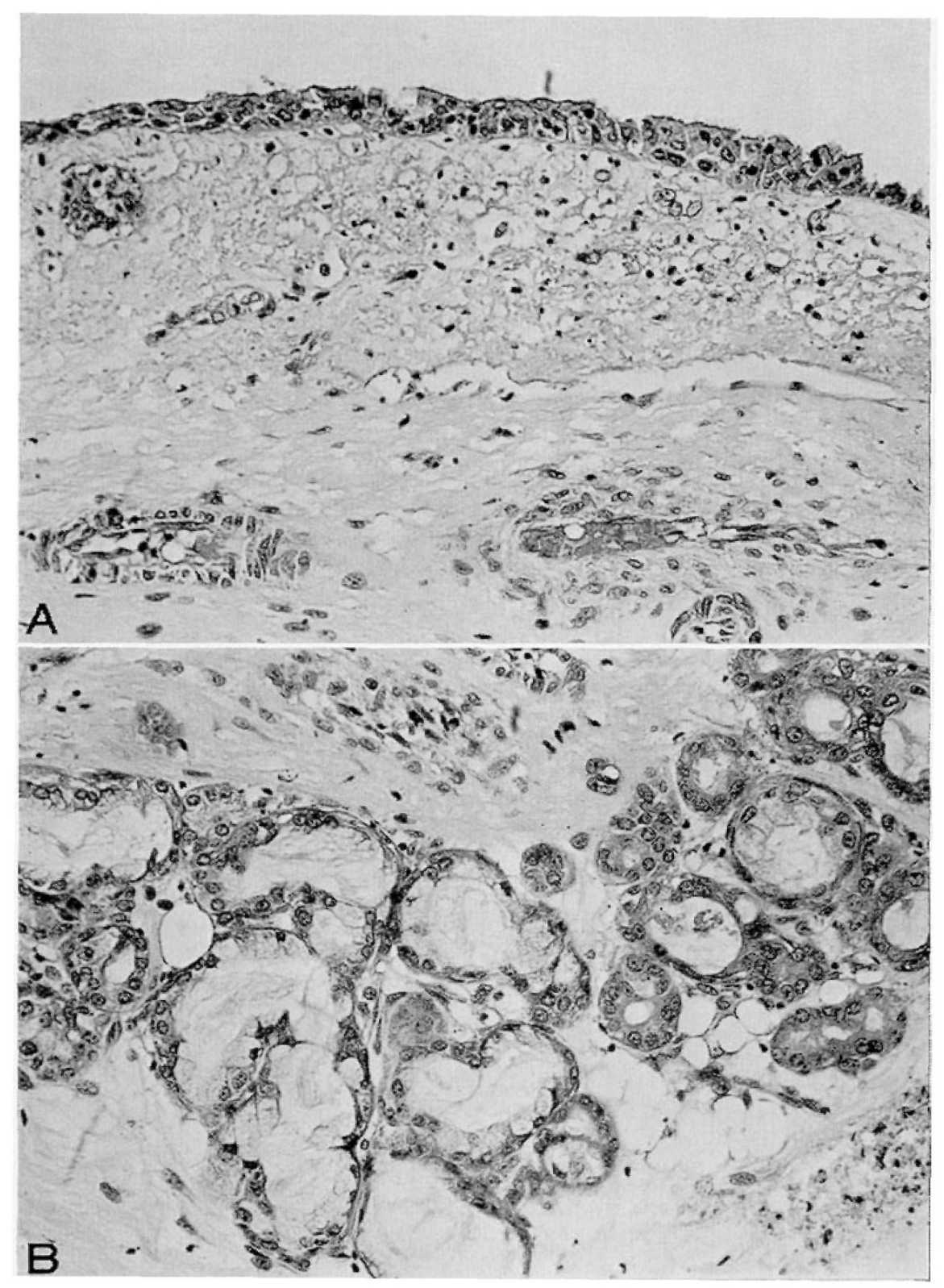

Fig. 4. A: 96 -hr culture, $80 \%$ oxygen. The surface epithelium is largely squamous; only a few ciliated cells are present. Within the epithe lium individual cell pyknosis and degeneration are present. The submucosa is edematous and contains many degenerating leukocytes. $\times \quad 250$; hematoxylin and eosin. B: 96 -hr culture, $80 \%$ oxygen. Submucosal glands are well preserved. Both serous and mucus gland ele ments can be seen. Many gland lumina contain fibrillar secretory material. $X \quad 250$; hematoxylin and eosin.

gen [9]. Other workers, however, were unable to confirm this observation in $\log$ tracheae [11]. These results emphasize the hazards of reaching general conclusions on the basis of studies conducted in one mammalian species.

The organ culture system used in the present study offers several advantages. (1) Oxygen toxicity studies can be carried out on human tissue. (2) Tissue from one source can be exposed simultaneously to two oxygen concentrations under otherwise uniform conditions. (3) The effect of oxygen can be studied sequentially for a relatively long duration, i.e., 7 days or more. Long term observations in this series of controlled in vitro experiments demonstrate conclusively that oxygen is toxic to human large airways epithelium. 


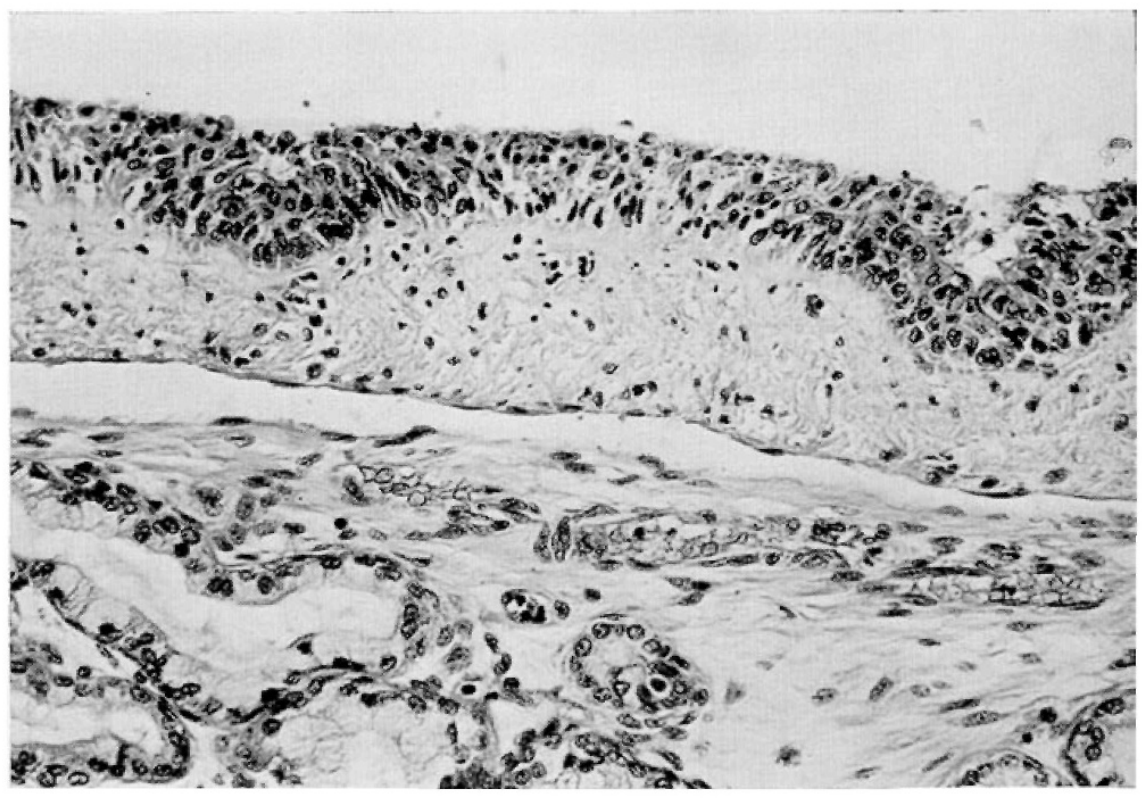

Fig. 5. One hundred sixty-eight hour culture, $80 \%$ oxygen. The surface epithelium is squamous and exfoliating. No ciliated cells can be seen; cell layers are poorly organized. The submucosal glands are well preserved, predominantly mucus in character, dilated, and show retained luminal secretion. $\times \quad 250$; hematoxylin and eosin.

It is not yet certain that this observation can be extrapolated to the in vivo situation. However, several pieces of evidence clo inclicate that the changes of oxygen toxicity may be similar in vitro and in vivo. Ciliated cells appear in tracheal secretions of the neonate within 3 days after initiation of therapy with $\mathrm{HiO}$ [14]. Manifestations of bronchopulmonary dysplasia, both clinical and radiographic, generally are observed after 4 or 5 days of exposure to $\mathrm{HiO}$. This time sequence is consistent with the appearance of changes in ciliary motility and epithelial morphology of cultured respiratory epithelium exposed to $80 \%$ oxygen.

The clinical implications of these observed changes may be of therapeutic importance. These changes in intact airways would eliminate mucociliary function, a primary defense mechanism of the lung. Expected sequelae would be accumulation of secretions, defective clearance of particles, and predisposition to lower respiratory tract infection. These sequelae may in turn cause severe obstructive changes in conducting airways. Under these circumstances the early use of therapy designed to assist in the clearance of secretions would be indicated.

The alteration of mucin secretion by cultured respiratory epithelium after exposure to $\mathrm{HiO}$ is also potentially important. Increased secretion of mucin and lysozyme by explants for the first 24-48 hr of culture in $\mathrm{HiO}$ may have resulted from better preservation of deep submucosal glands. On the other hand, $80 \%$ oxygen may have been an irritative stimulus causing hypersecretion, especially from goblet cells of the surface epithelium. It will be important to ascertain whether hypersecretion occurs soon after introduction of $\mathrm{HiO}$ to infants with respiratory distress.

The reduction of secretion by explants after 3 days of exposure to $80 \%$ oxygen is surprising in view of the excellent submucosal gland preservation in explants exposed to this environment. It is difficult to ascribe this reduction of secretion to the loss of goblet cells, inasmuch as these cells of the surface epithelium comprise a total mass much smaller than the mass of mucus-secreting cells in submucosal glands [8]. The accumulation of large amounts of intracellular and intraluminal mucin seen in glands of explants exposed to $80 \%$ oxygen suggests that discharge of the accumulated secretory product was hindered. This suggestion is further supported by preliminary studies from our laboratory which show a four- to fivefold increase of nondialyzable ${ }^{35} \mathrm{SO}_{4}$ and tritium, and a two- to threefold increase of macromolecular fucose and sialic acid in the $20,000 \times g$ supernatant fraction of homogenates of washed explants cultured in the presence of $\mathrm{HiO}$ for 7 days.

It appears that $\mathrm{HiO}$ concentrations in some way interfere with the discharge of mucin produced in submucosal glands. This interference is detected at the 
same interval after exposure as is cessation of ciliary activity on the surface epithelium. We suggest that inhibition of ciliary motility in the ciliated portion of the submucosal gland duct may be the mechanism by
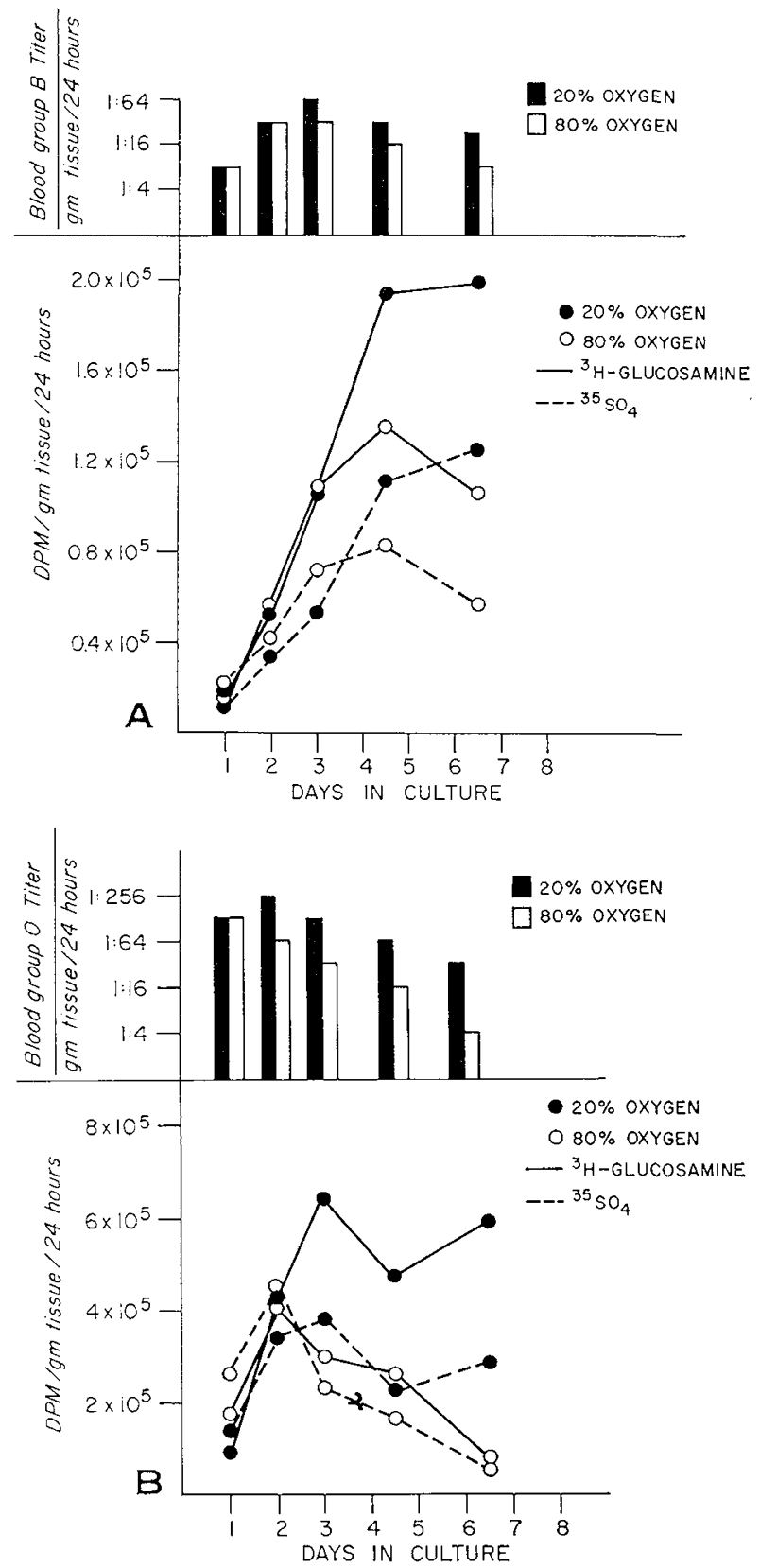

Fig. 6. Secretion of tritiated and sulfated macromolecules, and of blood group substance, in the presence of $20 \%$ and $80 \%$ oxygen by tracheal explants from neonates who died of hypoplastic left ventricle $(A)$ and asphyxiating thoracic dystrophy $(B)$. Media from days 4 and 5 and days 6 and 7 were pooled before analysis of samples from each of the oxygen exposure groups, but data from these analyses are calculated on a $24-\mathrm{hr}$ basis.

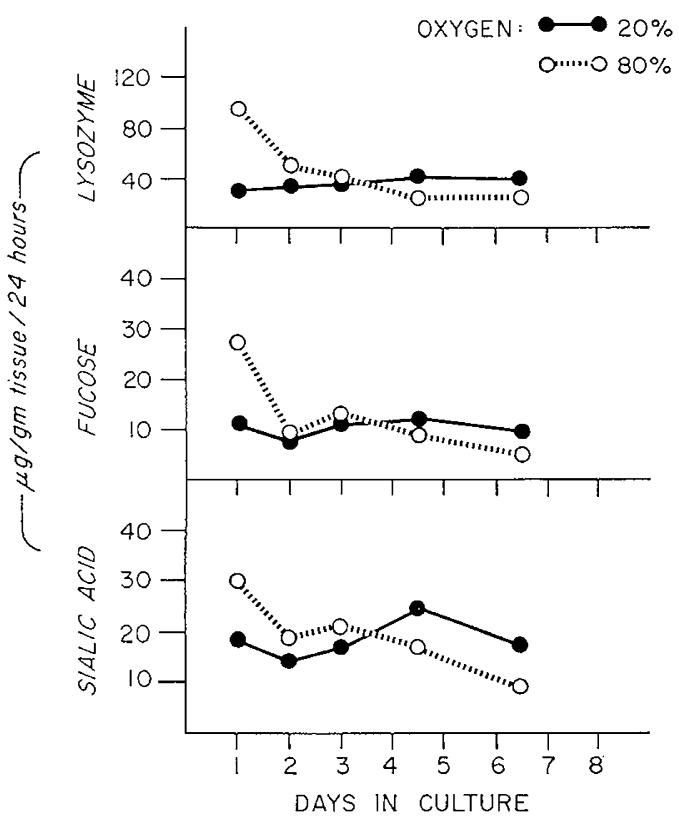

Fig. 7. Secretion of lysozyme and macromolecular fucose and sialic acid in the presence of $20 \%$ and $80 \%$ oxygen by tracheal explants from the infant who died of asphyxiating thoracic dystrophy.

which mucin discharge is prevented. Alternatively, $\mathrm{HiO}$ may interfere with the function of myoepithelial cells which presumably assist in the movement of secretions from the distal portions of the glands [10].

It is also possible that $\mathrm{HiO}$ oxidizes the sulfhydryl groups of mucin molecules, resulting in more intermolecular disulfide bonds [2], and subsequently in more viscous secretions which cannot be as easily expelled from the glands.

\section{Summary}

Human neonatal tracheal epithelium which has been cultured in the presence of $80 \%$ oxygen for at least 48 hr shows marked changes of ciliary function and mucus secretion. These changes, including cessation of ciliary movement, loss of ciliated surface epithelium, and initial hypersecretion followed by hyposecretion of mucin, were not observed during culture of explants from the same source in 20\% oxygen for 7 days. The times of onset for changes induced by oxygen in vitro and the development of cytologic and roentgenographic evidence of bronchopulmonary dysplasia are strikingly similar and suggest that the alterations observed in cultured neonatal trachea also occur in the neonate exposed to high concentrations of oxygen. 


\section{References and Notes}

I. Boat, T. F., Iyer, R. N., Macintyre, M. D., Carlson, D. M., and Matthews, L. W.: Evaluation of a culture method for study of human tracheobronchial secretion (Abstract). Amer. Rev. Resp. Dis., 103: 915 (1971).

2. Bont, T. F., and Matthews, L. W.: Chemical composition of human tracheobronchial secretions. In: M. Dulfano: Sputum. (Charles C Thomas, Springfield, Ill., 1973).

3. Clements, J. A., And Fisher, H. K.: The oxygen dilemma. New Engl. J. Med., 282: 976 (1970).

4. Davis, B. J.: Disc electrophoresis. Ir. Method and application to human serum proteins. Ann. N. Y. Acad. Sci., 121: 404 (1964).

5. Dische, Z., and Danilchenko, A.: Modifications of two color reactions of hexoses with cysteine and sulfuric acid. Anal. Biochem., 21: 119, (1967).

6. Hoorn, B.: Organ cultures of ciliated epithelium for the study of respiratory viruses. Acta Pathol. Microbiol. Scand. Suppl., 183 (1966).

7. KABAT, E. A., AND MAYER, M. M.: Experimental Immunochemistry, p. 127. (Charles C Thomas, Springficld, Il1., 1961).

8. KILBURN, K. H.: A hypothesis for pulmonary clearance and its implications. Amer. Rev. Resp. Dis., 98: 449 (1968).

9. Laurenzr, G. A., Yin, S., and Gunrneri, J. J.: Adverse effect of oxygen on tracheal mucus flow. New Engl. J. Med., 279: 333 (1968).

10. Leeson, T. S., and Lerson, C. F.: Histology, p. 91. (W. B. Saunders Co., Philadelphia, Pa., 1970).

11. Maris, M. G., ANd Morrow, P. E.: Effect of changing inspired
$\mathrm{O}_{2}$ and $\mathrm{CO}_{2}$ levels on tracheal mucociliary transport rate. J. Appl. Physiol., 27: 385 (1969).

12. Mowry, R., AND Winkler, C. H.: The coloration of acidic carbohydrates of bacteria and fungi in tissue sections with special refcrence to capsules of Cryptococcus neoformans, pneumococci, and staphylococci. Amer. J. Pathol., 32: 628 (1956).

13. Northway, W. H., Rosan, R. C., and Porter, D. Y.: Pulmonary disease following respirator therapy of hyaline-membrane disease. New Engl. J. Med., 376: 358 (1967).

14. Northway, W. H., and Rosan, R. C.: Oxygen therapy hazards in the neonate. Hosp. Practice, 4: 59 (1969).

15. Osserman, E. F., AND LAWLor, D. P.: Serum and urinary lysozyme (muramidase) in monocytic and monomyclocytic leukemia. J. Exp. Med., 12f: 921, 1967.

16. WARrEn, L.: The thiobarbituric acid assay of sialic acids. J, Biol. Chem., 234: 1971 (1959).

17. Fungizone, Grand Island Biological, Grand Island, ‥ Y.

18. Mycostatin, Grand Island Biological, Grand Island, N. Y.

19. IMI Oxygen controller, B-D Electrodyne, Sharon, Mass.

20. The authors wish to thank Dr. Eugene Perrin and other members of the Department of Pathology for assistance in the prompt procurement of postmortem trachea specimens.

21. This research was supported in part by Grants nos. HL 14884 and AM 08305, United States Public Health Service, the Health Fund of Cleveland, and the Education Foundation of America.

22. Requests for reprints should be addressed to: Thosras F. ВолT, M.D., Rainbow Babies and Childrens Hospital, 2103 Adelbert Road, Cleveland, Ohio 44106.

23. Accepted for publication February 12, 1973. 